\title{
Construcción del concepto de economía solidaria: una mirada a la teoría económica comprensiva
}

\author{
Julián Mauricio Vélez-Tamayo*
}

* Magíster en Desarrollo, Universidad Pontificia Bolivariana. Investigador del Grupo ginveco. Miembro de la Red Unicosol, nodo Antioquia. Profesor, Facultad de Economía, Universidad Autónoma Latinoamericana (UNAULA), Medellín, Colombia. Correo electrónico: julianvelez@unaula.edu.co

Recibido: 19 de septiembre del 2014 Aprobado: 7 de noviembre del 2014

Cómo citar este artículo: Vélez-Tamayo, J. M. (2014). Construcción del concepto de economía solidaria: una mirada a la teoría económica comprensiva. Cooperativismo \& Desarrollo, 22(105), 17-29. doi: http://dx.doi. org/10.16925/co.v22i105.690

\begin{abstract}
Resumen
El artículo propone un viraje a la teoría económica tradicional a partir de los aportes de la teoría económica comprensiva de Luis Razeto Migliario (1994). Para ello, además de mostrar aspectos importantes de la teoría propuesta, se exponen los resultados de una aproximación desde la vivencia de la asociatividad de algunas organizaciones de carácter agropecuario en tres municipios del oriente de Antioquia, los cuales, lejos de concentrarse en el crecimiento del factor capital, se fortalecen en el crecimiento del factor comunidad mediante la potenciación de los demás factores (trabajo, medios financieros, medios materiales, tecnología y gestión). Estos se desenvuelven en el contexto de la economía campesina, concepto que se aborda desde la aproximación de Forero (2003), y se resalta el carácter familiar campesino de las organizaciones. Se evidencia que las características de las asociaciones estudiadas, aunque no tienen desarrollado unos fuertes factores financieros y materiales, están cohesionadas por valores que fortalecen el factor comunidad.
\end{abstract}

Palabras clave: economía campesina, economía solidaria, factor C, factor económico, teoría económica comprensiva.

\section{Construction of the Concept of Solidarity Economy: A Look at Comprehensive Economic Theory}

\begin{abstract}
The article proposes a shift in traditional economic theory based on contributions from the field of comprehensive economic theory by Luis Razeto Migliario (1994). To do so, in addition to showing important aspects of the proposed theory, the results are given from an approach based on the experience of associativity in certain agricultural and livestock raising organizations in three municipalities in eastern Antioquia. These organizations, rather than focusing on growth of the capital factor, are strengthened through growth of the community factor by boosting the other factors (work, financial means, material means, technology and management). The research takes place in the context of the farming economy, which is examined using the Forero approach (2003), and stresses the family farming nature of the organizations. It is clear from the characteristics of the association under study that, although they have not developed strong financial and material factors, they are held together by values that strengthen the community factor.
\end{abstract}

Keywords: farm economy, solidarity economy, C factor, economic factor, comprehensive economic theory.

Construção do conceito de economia solidária: um olhar sobre a teoria econômica compreensiva

\section{Resumo}

Este artigo propõe uma virada na teoria econômica tradicional a partir das contribuições da teoria econômica compreensiva de Luis Razeto Migliario (1994). Para isso, além de mostrar aspectos importantes da teoria proposta, expõem-se os resultados de uma aproximação a partir da vivência da associatividade de algumas organizações de caráter agropecuário em três municípios do leste da Antioquia (Colômbia), os quais, longe de se concentrarem no crescimento do fator capital, se fortalecem no crescimento do fator comunidade mediante a potenciação dos demais fatores (trabalho, meios financeiros, meios materiais, tecnologia e gestão). Estes se desenvolvem no contexto da economia camponesa, conceito que se aborda com base em Forero (2003), e ressalta-se o caráter familiar camponês das organizações. Evidencia-se que as características das associações estudadas, embora não tenham desenvolvido fortes fatores financeiros e materiais, estão coesas por valores que fortalecem o fator comunidade.

Palavras-chave: economia camponesa, economia solidária, fator C, fator econômico, teoria econômica compreensiva. 


\section{Introducción}

La economía solidaria o la economía de la solidaridad, según el profesor Razeto, se constituye, para muchos, en una nueva opción alternativa de producción, mucho más después de la caída del bloque soviético y el fin de la llamada Guerra Fría. Sin embargo, experiencias relacionadas con la economía solidaria, tales como el cooperativismo, el mutualismo o las empresas autogestionadas, no surgen en el mundo posterior al final de estos acontecimientos. Por el contrario, muchas de ellas surgen ante situaciones particulares de necesidades de comunidades específicas.

La importancia de abordar una investigación en la que se identifiquen y caractericen asociaciones y cooperativas de pequeños y medianos productores agropecuarios está limitada por aspectos puntuales tales como la hegemonía del pensamiento ortodoxo en la economía (el cual concibe los factores productivos relacionados exclusivamente con la tierra, el trabajo y el capital). Precisamente, en ese sentido, se establece lo que se denominará el viraje. En el artículo no se conciben los medios de producción en términos convencionales; no existen las categorías de capital y trabajo, sino que se toman unas nuevas. Para realizar un análisis comprensivo de la realidad de estas organizaciones, se hace necesaria una posición como la ofrecida por la teoría económica comprensiva, la cual propone unos factores de carácter más amplio, al punto de que permite involucrar los tradicionales. En efecto, no se trata de hacer un análisis desde las formas de propiedad de los medios de producción tradicionales - las cuales no se tienen en cuenta en este artículo- puesto que estos son concebidos a la luz de una teoría diferente. De igual forma, no las puede estudiar, dado que no concibe - desde la propuesta teórica - una estructura tradicional.

Por tanto, el documento permite identificar los nuevos saberes desde el análisis de los factores, explicados a la luz de la teoría económica comprensiva. En esta se sostiene la propuesta de la economía de solidaridad, formulada por Razeto (1994), dentro de la realidad observada en un territorio específico.

\section{Aproximación hacia una comprensión de la economía capitalista}

El mercado capitalista se determina mediante las diferentes versiones o estructuras de mercado, las cuales se estudian desde la microeconomía: competencia perfecta, oligopolio, monopolio y monopsonio. De estas opciones, solo se puede observar en la realidad el oligopolio y, quizás, el monopsonio. Para los otros casos, hay condiciones en que se acercan los modelos a la realidad, pero no se cumplen la totalidad de los supuestos. El ejemplo real que más se utiliza para el caso de competencia perfecta es el de una plaza de mercado. Sin embargo, si bien puede haber muchos oferentes y muchos demandantes, no necesariamente se cumple el principio de "libre movilidad", así como no se cumple el supuesto de "libre acceso a la información" y, sobre todo, los precios no necesariamente son determinados por el "mercado", sino que pueden ser afectados por algún tipo de autoridad (no necesariamente política). Además, la tasa de beneficio no tiende a cero; en algunos casos se torna negativa, por lo que no es posible aseverar que efectivamente existe un mercado de competencia perfecta en la realidad según los planteamientos teóricos.

La competencia como concepto surge de una acción egoísta de "adquirir ventaja", fundamento, en todo caso, del mercado capitalista. El desarrollo de la economía capitalista está determinado por el desarrollo teórico de pensadores como Adam Smith (1776), quien establece el egoísmo como principal elemento motivante de las relaciones económicas. Smith, como escocés que era, tenía fuertes influencias protestantes de tipo calvinista, lo cual permitía el tratamiento de los conceptos de interés y, con ello, los orígenes de la actividad financiera (contraria a la posición tradicionalmente católica de Santo Tomás de Aquino, que consideraba “inmoral" el cobro o efecto de los intereses, identificándolo con la usura y, por lo tanto, con el pecado).

La teoría económica tradicional, además, identifica tres factores de producción importantes: la tierra, el trabajo y el capital, con sus respectivas retribuciones y remuneraciones. En este sentido, la tierra, por la participación en el proceso de producción, hace que su poseedor - normalmente conocido como terrateniente (teniente de la tierra o tenedor de tierra) - reciba una contribución o retribución por permitir que su propiedad participe en el proceso productivo; a esta retribución se le conoce como renta de la tierra o simplemente renta. De igual manera, para el capitalista, por permitir que su capital participe en el proceso de producción, se le retribuye con una tasa de ganancia o tasa de interés, de forma que permite la reproducción de este factor primordial en el modo de producción capitalista. En el caso del dueño del factor trabajo (el trabajador), no es que permita la participación de su desgaste de energía, 
sino que se ve obligado a vender su mano de obra y tendría una retribución por ello; esta sería la remuneración que le corresponde, es decir, el salario.

\section{Indagaciones sobre la economía social y solidaria a partir de la propuesta del pensamiento económico tradicional}

¿Puede pensarse la economía social y solidaria como una propuesta alternativa al modo de producción capitalista, en cuanto modo de producción solidario? Es común la comparación entre la forma capitalista de la economía y las denominadas alternativas, identificables con los caminos de la economía solidaria. Sin embargo, no se ha establecido si la economía solidaria cumple las condiciones en sí mismas para configurarse como un modo de producción, desde el punto de vista de la economía política.

Es claro que la intencionalidad de la economía social y solidaria no es la de involucrarse como un "modo de producción"; de hecho, la evidencia histórica ha demostrado que puede germinar semilla de economía solidaria en modos de producción de transición, como lo es el socialista, además de aflorar en las diferentes versiones de la estructura capitalista. Inclusive, podría decirse que en modos de producción como el esclavista se vieron aspectos propios de la economía solidaria, tales como los mencionados en el libro de los hechos de los apóstoles y en la estructura feudal, con la formación de grupos como los valdenses y otros grupos calificados como heréticos en la Edad Media.

Por tanto, esta forma de economía supera las dimensiones propias de una estructura productiva denominada modo de producción y se constituye en una categoría superior, aún pendiente de establecer desde el punto de vista conceptual, el cual no se propone desarrollar este artículo.

¿Es posible aseverar que los factores productivos tradicionalmente son una expresión reducida de los factores económicos propuestos por la teoría económica comprensiva, en cuanto el reduccionismo de los mismos no logra explicar la totalidad de los fenómenos económicos que afectan las unidades productivas? Precisamente, supera paradigmas porque la forma de economía social y solidaria se constituye en una categoría superior (puesto que la forma de asimilar los factores ha de ser epistemológicamente distinta y diferenciada). Por esto se dice que es "superior", siendo al mismo tiempo diferente y diferenciadora, de manera que no se excluye la tradicional forma de considerar los tres factores productivos. Esto permite que la tradicional sea un caso particular de la visión propia de la economía solidaria, si bien para ello se hace necesario teorizar más, de tal manera que permita el desarrollo de una propuesta académicamente seria, científicamente aceptable y socialmente aplicable.

Ahora bien, si el determinante o elemento que mueve la economía capitalista es el egoísmo, según la posición de Smith (1776/1958), cuando dice: "Al buscar su propio interés, el hombre a menudo favorece el de la sociedad mejor que cuando realmente desea hacerlo". ¿La fraternidad o solidaridad misma podría ser el elemento que mueve la economía social y solidaria?

Sería este el camino para garantizar la formulación epistémica de la economía solidaria. La propuesta solidaria, desde el punto de vista histórico, ha de tener un mayor bagaje que garantice la formulación científica que se reclama. Definir epistemológicamente una teoría desde la vivencia axiológica se constituye en una tarea ardua y difícil, pero que puede tener la suficiente ilustración y demostración casuística e histórica que le permita acceder a las discusiones académicas de hoy y de mañana, con la rigurosidad que esta demanda. La filosofía de la economía social y solidaria busca un apoyo recíproco entre las entidades que profesan este sistema; sin embargo, en la praxis la economía solidaria es un centro de cooperación, de reciprocidad.

\section{Una propuesta de conformación del sector de la economía solidaria}

Tanto el capitalismo como el socialismo son sistemas económicos con importantes defectos; tarde o temprano resultan terriblemente injustos. Por lo tanto, la economía solidaria puede ser también una economía basada en los principios de otras propuestas alternativas. Se busca, como economía solidaria, el equilibrio entre el bien común y la libertad personal asentados en la justicia, la equidad y la proporcionalidad. Sin embargo, la economía solidaria no es propiamente comparable con el capitalismo o el socialismo, sino que puede hacer parte de la economía basada en la doctrina social de la Iglesia, por lo que esta la alimenta.

No es comparable en el sentido de que la economía solidaria no tiene el deseo o la presunción de asimilarse como un modo de producción. Y no lo es, en cuanto no alcanza a cubrir los aspectos de un sistema de este tipo, ya que si bien se establece como estructura productiva con la interacción de los factores económicos (medios materiales, medios financieros, tecnología, gestión, 
trabajo y factor C), no es así en términos de estructura de poder, pues no entiende la jerarquización de los factores y, por lo tanto, no se evidencia existencia o diferenciación de clases ni una relación de dominación. Es por esto que la economía solidaria puede incorporarse tanto en una estructura capitalista, en cuanto puede establecer relaciones con estructuras de poder que jerarquizan el capital (medios financieros y medios materiales), o con estructuras que jerarquizan el trabajo, como usualmente se ha hecho durante los últimos dos siglos.

Por tanto, considerar la economía solidaria un modo de producción propiamente dicho no tiene sentido; sencillamente no es la intencionalidad de esta propuesta, y si lo fuera, dejaría de ser economía solidaria.

Lejos de la conformación de un bloque teórico y una estructura académica definida, como el caso de las posiciones de varias escuelas de pensamiento económico, la economía de la solidaridad es una respuesta pragmática a una situación de necesidad. No se trata con esto de desmeritar la acción misma de la economía de la solidaridad, y mucho menos cuando se dice que, precisamente, supera la frontera cronológica del capitalismo y que sus postulados obedecen a una categoría superior. Para la mayoría de economistas, la denominada economía solidaria no es una propuesta novedosa que permita pugnar con las teorías económicas convencionales, en efecto, por carecer, de facto, de un pensamiento estructurado como estructura productiva. Por otro lado, para muchos, la opción cooperativista es una respuesta ante las injusticias de un sistema capitalista enfermo.

Sin embargo, esta opción cooperativista está plagada de idealismo, doctrina e, inclusive, una especie de realismo mágico ensordecedor, el cual pareciera mostrarlo como la panacea a las dificultades sociales, de manera que posiciona este camino a la economía de la solidaridad como única expresión de esta, quedando en un reduccionismo que poco ayuda al entendimiento de la propuesta de la teoría económica comprensiva.

Observada por separado de las demás corrientes o caminos de la economía de la solidaridad, no es posible equiparar o jerarquizar la propuesta cooperativista a un nivel de modo de producción (como lo han hecho muchos o, por lo menos, como lo han mostrado muchos apologistas de esta forma asociativa, justo cuando se equipara al capitalismo). Esto desdibujaría la intencionalidad de la economía solidaria en su conjunto, si bien durante mucho tiempo se consideró que el cooperativismo era igual o equivalente a la economía solidaria.
Un ejemplo de lo anterior es la postura de Jiménez-Arcila (1930), que considera la cuestión social algo primordial, al punto que su categoría de análisis sea la "sociología de la cooperación" - en la cual surge y se fundamenta el pensamiento cooperativista-. Esto con base en los teóricos solidaristas derivados de la pastoral de la Rerum Novarum, de manera que la solidaridad se reduce a cooperación.

Las economías solidarias funcionan perfectamente dentro de la lógica de una estructura capitalista, así como históricamente funcionaron dentro de estructuras feudales, esclavistas e inclusive propuestas de carácter comunista, como se verá un poco más adelante. Esto sucede, no porque se contrapongan a estas estructuras o sistemas, sino porque, como bien lo dice Razeto (2014), obedecen a necesidades y estas necesidades no se delimitan a un determinado modo de producción. Estas formas solidarias son desarrolladas por Razeto dentro de lo que denomina "Caminos de la Solidaridad", lo cual se abordará más adelante.

La intencionalidad misma de la economía solidaria está determinada en el libro de los hechos de los apóstoles (Hch 2, 44-47): "vendían sus posesiones y los repartían a todos según la necesidad de cada uno [...] partiendo el pan en las casas, comían juntos con alegría y sencillez de corazón". En últimas, es en lo que se funda la doctrina social de la Iglesia, aunado a lo escrito en Rerum Novarum del papa León XIII.

La disciplina económica se define como la ciencia que estudia los procesos de producción, distribución y consumo de bienes y servicios que son escasos. En este orden de ideas, es posible pensar en opciones solidarias u opciones de solidaridad diferentes de producción, distribución y consumo. De hecho, en la realidad las experiencias cooperativas, mutuales y experiencias similares precisamente se destacan por participar en estos aspectos (Guerra, 2008). Esto indica cómo la economía solidaria debe ser estudiada por la ciencia económica con profundidad y más específicamente por la economía política, dada su marginal consideración y la falta de claridad al respecto.

\section{Propuesta democratizadora del mercado: opción de la economía de la solidaridad}

Si se entiende la propuesta democratizadora diferente a la propuesta capitalista convencional, el primer paso es desmontar la fundamentación inicial de competencia, 
basado en el principio de egoísmo y de "adquirir ventaja", con el fin de garantizar que las relaciones económicas se basen en condiciones de igualdad. En otras palabras, si la opción capitalista se basó en propuestas originadas desde lo axiológico por una propuesta religiosa protestante de corte calvinista, el primer paso podría ser volver a la propuesta económica tradicionalmente católica o, por lo menos, compararla. Por ejemplo, que sea posible el no cobro de intereses, entendido este como el mecanismo por el cual un factor productivo, como es el factor financiero - en términos de la teoría económica comprensiva-, tenga una remuneración no necesariamente pecuniaria sin participar el proceso productivo, diferente a la posición capitalista, en la cual este factor genera una remuneración por el efecto de la tasa de interés, a pesar de no participar en el proceso productivo real.

\section{Un acercamiento a la teoría económica comprensiva}

Razeto (1997) hace la diferenciación entre recursos económicos y factores económicos. Los primeros son todos aquellos elementos, fuerzas materiales e inmateriales, naturales y humanas, que tengan la potencialidad de ser aprovechados en algún proceso o actividad económica, mientras que los factores económicos son todas aquellas fuerzas, elementos materiales e inmateriales, que participan actualmente en los procesos y actividades económicas. Es decir, son aquellos recursos que se encuentran organizados económicamente. Podría decirse, por tanto, que la diferencia entre los recursos y los factores está determinada en la participación efectiva dentro del proceso de producción, el cual siempre será un proceso de tipo económico. En este orden de ideas, los recursos pueden convertirse en factores, de manera que este proceso de conversión supone la "valorización económica de estos recursos o medios" (p. 39).

En relación con las intencionalidades del estudio que se realizó en los municipios del oriente de Antioquia, para el análisis se consideran inicialmente los factores medios materiales y medios financieros, ambos asimilables al tradicional factor capital, propuesto por la teoría económica tradicional.

\section{Factor medios materiales}

Constituye todos los elementos físicos: instalaciones, instrumentos, equipamiento, insumos y materias primas. En general, todo lo referente a propiedad, planta y equipo, maquinaria, equipo de transporte, equipo de comunicación y computación, equipo de oficina, muebles y enseres, inventarios, construcciones y edificaciones, terrenos y demás bienes y enseres que se mantienen en el interior de la organización y que están relacionados, directa o indirectamente, con el proceso de producción.

\section{Factor financiero o medios de pago}

Este factor constituye el dinero disponible y en inversiones, capacidad de crédito y, en general, todo lo que permite contratar los demás factores y establecer relaciones económicas en el mercado (intercambio y distribución). La representación del factor financiero normalmente es el dinero, aunque no necesariamente en todos los momentos y las condiciones se represente pecuniariamente.

En los procesos de producción, uno de los factores se constituye como factor organizador de unidades y actividades económicas; en efecto, en la economía convencional o en las llamadas empresas convencionales o capitalistas, el factor organizador lo asume el factor financiero o de medios de pago, en cuanto es este el que permite establecer relaciones de contratación con los demás factores. Es decir, los medios de pago permiten relaciones contractuales con los demás factores en cuanto permiten la compra o alquiler de materiales, maquinaria, propiedad, equipo, muebles, enseres, vehículos, equipo de transporte, inventarios (en general todo lo que constituye los medios materiales). Asimismo, contrata mano de obra (factor trabajo), compra mejoras tecnológicas (know how, patentes, procesos de innovación) y permite el desarrollo de actividades administrativas, pues reconoce la consecución de material y personas que desarrollen esta actividad. Es por ello que suele identificarse a este factor con el tradicional factor capital. Sin embargo, el capital trasciende todos estos factores y es solamente diferenciable con el factor comunidad, en el cual el capital asume una condición distinta y diferenciable a la de recursos económicos o factores económicos, a fin de configurarse en una categoría económica, es decir, se configura como un factor que asume la condición de organizador de las unidades económicas, de manera que permite convocar, subordinar, guiar o controlar los demás factores (Razeto, 1997). En otras palabras, en las economías capitalistas convencionales, el factor financiero, identificado como capital, asume la condición de categoría económica. 
Las pequeñas asociaciones o cooperativas campesinas carecen de un fuerte factor financiero o de medios de pago, por lo que su actividad no está organizada por el factor financiero y, en consecuencia, el capital no asume condiciones de categoría (como sucede en la empresa capitalista convencional). Si bien es cierto que muchas de estas sociedades, asociaciones y cooperativas siguen la existencia y la actividad productiva durante un tiempo, no sobreviven precisamente por la existencia del capital en abundancia. Se sabe que los campesinos aportan en sus asociaciones medios materiales de su propiedad personal, y es con estos medios que se constituyen como asociaciones o cooperativas (según el caso legal colombiano), ya que es mediante esta forma que logran "subsistir", en cuanto permanecen con la actividad productiva durante un periodo de tiempo.

Para Razeto (1997), la valorización de los medios materiales es el objetivo económico de las empresas feudales, de tal manera que "los demás factores se encuentran subordinados de dicha categoría en ese tipo de unidades económicas" (p. 136), por lo que es en una estructura feudal en donde los medios materiales se constituyen como categorías; es decir, se establecen como organizadores de los demás factores que asumen como subordinados del factor medios materiales.

Se hace necesario tener en cuenta este aspecto para el desarrollo del análisis, ya que salta la pregunta: ¿la economía campesina asume condiciones de feudalidad, o hay elementos de la economía campesina comunes a una estructura feudal? Sin duda, no se trata de expresar una relación de feudalidad, en unas relaciones de producción propias de la lógica capitalista, en cuanto las organizaciones de economía campesina están íntegramente ligadas a las lógicas del mercado (Forero, 2003), e involucran, aunque de manera limitada, el factor capital, aunque no logre establecerse para estos casos como categoría económica.

Podría decirse, más bien, que existen una serie de elementos que no son constitutivos de la economía campesina a la feudalidad, en cuanto la tierra asume condiciones de protagonismo, es decir, hay dominio sobre una extensión (también limitada) de terreno que es utilizado para la explotación productiva. Además, no intermedian remuneraciones al trabajo, como en la economía capitalista convencional, sino que las remuneraciones están determinadas en especie y por el hecho de pertenecer a un grupo social que, según los casos, puede ser la familia. Sin embargo, estos elementos no pueden tampoco determinar el hecho de que una estructura de producción como la campesina sea de carácter feudal.

\section{Factor C (comunidad): categoría económica en la economía social y solidaria}

Con la existencia del factor $\mathrm{C}$ en las organizaciones comunitarias, comunales y cooperativas, se despliegan modos propios de producir, distribuir, consumir y acumular con solidaridad (Razeto, 1994). Las organizaciones que manifiestan la existencia de este factor se agrupan en el sector de economía solidaria. Este factor permite la formación de un grupo, asociación o comunidad que opera cooperativa y coordinadamente, además de proporcionar un conjunto de beneficios a cada integrante.

En este orden de ideas, si se pudiera establecer el centro, es decir, el factor $\mathrm{C}$ en condiciones de cohesión, podría generarse una dinámica que denominaríamos factor C-céntrica, la cual alimente los demás factores, de manera que los caminos de la economía de la solidaridad identificados con el respectivo peso de su factor, en sus condiciones particulares, puedan ampliarse. Esto no como una construcción atomizada de organizaciones y asociaciones, sino de una mega organización que permita una constante retroalimentación.

Algunas organizaciones capaces de alimentar esta condición pueden ser: cooperativas de trabajo asociado, encargadas de garantizar el factor trabajo; universidades, encargadas de garantizar gestión; cooperativas de ahorro y crédito o financieras, encargadas de garantizar medios financieros; organizaciones, fundaciones y corporaciones solidarias, encargadas de dotación de medios materiales; cooperativas productoras, comercializadoras e industriales, encargadas del factor tecnológico. Todas alimentando el centro de la economía solidaria, es decir, el factor C. Esto propiciaría la necesidad de que la economía solidaria sea factor C-céntrica.

\section{Descripción de los “caminos" de la economía solidaria}

En Colombia, la economía solidaria está definida, desde el punto de vista institucional, por la Ley 454 de 1998 que concibe la economía solidaria como:

[Un] sistema socioeconómico, cultural y ambiental conformado por el conjunto de fuerzas sociales organizadas en formas asociativas identificadas por prácticas 
autogestionarias solidarias, democráticas y humanistas, sin ánimo de lucro para el desarrollo integral del ser humano como sujeto, actor y fin de la economía (art. 2).

Sin embargo, para el objeto de este texto, no necesariamente se acogerá este concepto, dado que su objeto es la presentación de una alternativa epistémica a la visión ortodoxa de la economía, recurriendo a los postulados de la teoría económica comprensiva.

Para Razeto (1997), es posible llegar a la economía de la solidaridad por algún "camino", es decir, formas o expresiones de economía solidaria que no la constituyen de forma completa, sino que se aproximan a esta en cuanto se desarrolla en algún grado el factor C. Es posible alcanzar la economía solidaria. Se hace el análisis desde estas características cualitativas y sociales, precisamente porque lo que se busca es presentar una propuesta que traspasa los límites del paradigma, tanto científico como epistémico. Por tanto, no es posible criticar al capitalismo con medios capitalistas; esto no tiene sentido, dado, principalmente, a que se tiene el riesgo de quedar en apología. De hecho, se es muy explícito en el texto al decir que la economía solidaria supera, en términos históricos, la etapa del capitalismo al encontrarse, incluso, en otros modos de producción.

\section{Desde la pobreza}

Las características de atraso y poco desarrollo acomodadas, por ejemplo, a la economía campesina, se deben en gran medida a la falta de consideración por parte de la economía convencional a este tipo de expresiones. Estos atrasos normalmente son calificados como pobreza, dada la imposibilidad de consecución de bienes adicionales (modernos) por parte de la población que forma estas comunidades. Formas de organización campesina se "organizan" mediante modalidades de convites, en los cuales la comunidad, desde sus limitados recursos, generan acciones de cooperación y mutualidad aportando desde saberes hasta fuerza de trabajo para la consecución de una obra que beneficie a la comunidad. Esta forma de organización en Colombia se institucionaliza con la existencia de las Juntas de Acción Comunal, que funcionan tanto en la zona urbana como rural.

\section{Condición de trabajo}

Más que las condiciones mismas de trabajo, es la falta del trabajo mismo lo que genera situaciones de pobreza. En Colombia, a partir del proceso denominado de "apertura económica", se han incrementado las denominadas cooperativas de trabajo asociado. El problema de esta clase de organizaciones se debe a la incursión del Gobierno en los diferentes niveles administrativos en la gestión y estímulo a esta clase de organizaciones, lo cual, si bien soluciona el problema inicial de desempleo y de subyugación o subordinación (en cuanto no son empleados de una empresa determinada), permite condiciones de desfavorabilidad para con otros trabajadores de un mismo nivel y área. De hecho, Confecoop (2009) hace un reconocimiento de esta situación cuando fundamenta el crecimiento de este tipo de organización a partir de los incrementos en los costos de las nóminas originados por los pagos de salud, pensión y riesgos laborales. Esto permitió lo que se conoce como tercerización de la mano de obra y fue utilizado por los gobiernos, por ejemplo, para abaratar los costos en los hospitales públicos.

\section{Existencia de privilegios}

Ante una situación de violencia, el privilegio no es solamente el hecho de "tener más", también son los que no han vivido la situación de violencia. En este sentido, adicional al hecho de que muchos consiguen individualmente riqueza con la formación de negocios, se constituyen corporaciones, fundaciones o asociaciones.

\section{Situación de la familia y la mujer}

Por las condiciones de violencia en algunas regiones del país y del departamento, muchas familias quedaron sin "cabeza masculina": sin padre, sin hermano mayor. Sólo las mujeres asumen esta condición de "cabezas de familia" en una familia también disímil; abuelos y niños pequeños encerrados en los linderos de sus parcelas. Se constituyen entonces economías campesinas de trabajo familiar para la autosubsistencia, pero también existe la posibilidad de compartir con la familia vecina el común denominador de seguir caminando en el mundo sin la esperanza y protección paterna. Por eso, se organizan aprovechando la existencia de convites, no necesariamente lideradas por las Juntas de Acción comunal, sino por la necesidad de sobrevivir y alcanzar el aprovechamiento de los recursos que da la parcela.

\section{Crisis del cooperativismo}

Este sector (cooperativo) quizás fue uno de los que más sufrió durante la crisis económica que afrontó el país 
en 1999. Muchas de las cooperativas de ahorro y crédito tuvieron que desaparecer. Otras, que servían a este sector financiero siendo de carácter multiactivo, tuvieron que repensarse y configurarse en la especialización de cada una de las actividades económicas de consumo, producción, comercialización, servicios de corte financiero y servicios sociales. Son organizaciones que se gestionan no como apéndice del modo capitalista, sino como autogestionarias de su propio desarrollo. Con esto, no se establece que sea la crisis financiera de los noventa lo que permitió el surgimiento del cooperativismo, sino que, gracias a la crisis de corte capitalista, el sector cooperativo se vio afectado de tal manera que muchas de las formas y estructuras de las cooperativas fueron abolidas o reestructuradas, y los servicios de las cooperativas de ahorro y crédito se replantearon para obedecer a las lógicas de la estructura capitalista.

\section{Voluntad social de procesos transformadores}

Propuestas realizadas por jóvenes - y no tan jóvenesque quieren apostar por formas distintas de organización, no sólo productiva, sino también de impacto social, con el fin de aportar al desarrollo de su comunidad mediante actividades tales como la enseñanza, tan necesaria para emprender caminos de ocupación laboral e introducirse a la economía convencional.

\section{Economías ecológicas}

Propenden a la protección y mantenimiento del medio ambiente, ya que esto es lo que permite que las relaciones de producción tradicional persistan y sea posible sacar el fruto de la tierra que sirve como alimento y supervivencia.

\section{Otro desarrollo}

Propuestas más desde el discurso académico e inundado de ideologías, en el cual se encuentran posiciones radicales tales como feminismo, organizaciones populares que buscan la reivindicación de sus derechos, organizaciones étnicas, raciales y, sobre todo, organizaciones de víctimas que buscan la restitución de sus tierras, de sus derechos y de sus condiciones de víctimas de la violencia. Aunque se discute sobre su condición de "otro desarrollo" por sus posiciones de carácter dogmático, es común su grito desesperado por otras opciones de desarrollo. Son experiencias vivas de asociatividad que indican un transitar hacia la economía solidaria.

\section{Pueblos antiguos}

La vuelta a la estructura de la minga, entendida como una forma asociativa de trabajo y no como una organización que perdura en el tiempo, supone la posibilidad de asociatividad relacionada con los convites, formas de trabajo propias de los habitantes primigenios de la América Hispánica. Estos procesos, como se mencionó, son coordinados en Colombia por las Juntas de Acción Comunal.

\section{Contexto espiritual}

Se constituye en expresiones de fe, a partir de la formación axiológica que permite ver al vecino (más próximo) como el prójimo bíblico, "el hermano". Vivencias como estas son las evidenciadas en grupos como Cursillistas de cristiandad, Cáritas diocesano, Cáritas parroquial, Sociedad de San Vicente de Paúl, y Bancos Diocesanos de Alimentos. Son direccionados por la Iglesia, no solo como administradores de las obras, sino también visualizadas como formas de práctica cristiana o asimilación eclesial a las enseñanzas de Cristo.

\section{Economía campesina: camino hacia la economía solidaria}

Muchos de estos caminos se evidencian precisamente en la economía campesina. En efecto, es en condiciones de economía campesina que se identifican caminos tales como necesidades originadas por la pobreza, las condiciones de trabajo, la situación de la familia y la mujer, la voluntad social de procesos transformadores, la economía ecológica y los otros desarrollos. Aunados estos caminos a condiciones de vivencia de la solidaridad de los pueblos antiguos y la fuerte religiosidad de los habitantes rurales, se da un acercamiento a la economía solidaria. De allí la importancia de estudiar, caracterizar y analizar las asociaciones de este tipo de productores, de manera que surja una explicación más fuerte y se halle evidencia sólida de la consolidación de este tipo alternativo de economía. 


\section{Economía campesina}

Sería conveniente definir economía campesina como aquellas relaciones en las que una economía aún es muy rudimentaria (de "pan comer" o "pan coger"), y no hay presencia del capital financiero y eventual reproducción. De igual forma, en las que estas relaciones de producción no necesariamente están determinadas por el factor capital, desde el punto de vista convencional.

Según Forero (2003), el agro colombiano, en su estructura productiva, está compuesto por tres formas empresariales básicas, a saber: empresa agropecuaria capitalista, latifundio ganadero especulativo, y producción familiar y comunitaria. Este documento se centra en la producción familiar y comunitaria, y se identifica esta como economía campesina (tabla 1).

La economía campesina se entiende como la estructura productiva compuesta por una forma empresarial básica de producción familiar o comunitaria. Se involucran en esta forma de producción todos los productores forestales o pesqueros, así como las comunidades rurales en las cuales la economía comunitaria sustituye la producción familiar o la complementa. Su reproducción depende de la generación de ingresos (monetarios y en especie) a la familia o grupo social.

Tabla 1

Estructura agraria colombiana

\begin{tabular}{|c|c|c|}
\hline $\begin{array}{l}\text { Organización } \\
\text { productiva }\end{array}$ & Tipo & Modo \\
\hline \multirow{6}{*}{$\begin{array}{l}\text { Empresa capitalista } \\
\text { agropecuaria }\end{array}$} & Finca agrícola & \multirow{8}{*}{ 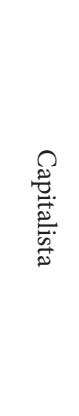 } \\
\hline & Empresa itinerante & \\
\hline & Plantaciones agroindustriales & \\
\hline & Hato ganadero tecnificado & \\
\hline & Hato ganadero extensivo & \\
\hline & Bioindustrias & \\
\hline $\begin{array}{l}\text { Empresa } \\
\text { especulativa }\end{array}$ & Latifundio ganadero especulativo & \\
\hline \multirow{4}{*}{$\begin{array}{l}\text { Economía } \\
\text { campesina }\end{array}$} & Producción familiar capitalista & \\
\hline & $\begin{array}{l}\text { Familiares altamente integrados al } \\
\text { mercado }\end{array}$ & \multirow{3}{*}{$\underset{\approx}{\stackrel{7}{\ddagger}}$} \\
\hline & Comunitarias & \\
\hline & Familares de autosubsistencia & \\
\hline
\end{tabular}

Nota. Adaptado de Economía campesina y sistema alimentario en Colombia: aportes para la discusión de la seguridad alimentaria en Colombia, por J. Forero, 2003.
Esta forma de organización productiva puede ser comunitaria, familiares de autosubsistencia y con alguna integración al mercado (Forero, 2003).

\section{Campesinado como grupo social}

El Estado colombiano no ha reconocido al campesinado como grupo social, "Muestra de ello es [...] que la categoría 'Campesino' no existe en las encuestas e información oficial lo que afecta las posibilidades de saber cuál es la situación de esta población y cómo atenderla" (PNUD, 2011, p. 64).

Como grupo social, el sector campesino sufre las terribles consecuencias de su falta de reconocimiento. Aspectos tales como el acceso a la tierra, al crédito, a la asistencia técnica, las continuas amenazas a la vida y dignidad a la que se ve expuesto y la limitada participación política lo evidencian. Este último se manifiesta en dos vías: por un lado, el difícil reconocimiento de su condición de ciudadanos, y la falta de reconocimiento de las autoridades en aspectos realmente importantes. A este sector de la población normalmente se les considera "votos adicionales", con los cuales es posible acceder a algún cargo público; además, es posible garantizarlos mediante la donación de algunos bienes o herramientas de los que ellos están necesitados:

La ausencia de reconocimiento como grupo social, su subvaloración en la actividad productiva en especial la de los pequeños propietarios la falta de distribución de la tierra, su victimización por parte de actores armados y su fragmentación política ha puesto al campesinado en una alta situación de vulnerabilidad (PNUD, 2011, p. 65).

Con respecto a la producción, la economía campesina participa activamente en la producción nacional de bienes del sector primario de la economía y produce "algo más de los alimentos que se consumen en Colombia” (PNUD, 2011, p. 64). La economía campesina se circunscribe en el contexto de la economía solidaria en cuanto son formas de organización comunitaria y, en la mayoría de los casos, no está determinada una relación de tipo productiva en términos capitalistas, sino que la organización productiva se fortalece y se basa en condiciones de familiaridad, vecindad y amistad, lo cual se constituye en elementos formalizantes del concepto de solidaridad. 


\section{Caracterización de organizaciones solidarias en el oriente antioqueño: casos Concepción, San Vicente Ferrer y Alejandría}

El estudio de las organizaciones solidarias en los municipios de Concepción, San Vicente Ferrer y Alejandría se abordó desde una perspectiva cualitativa, donde los asociados de las entidades de economía social y solidaria compartieron sus experiencias asociativas mediante la técnica de entrevista semiestructuralizada, lo cual permitió el acercamiento a la comprensión de sus realidades a partir de la propuesta razetiana. La caracterización permitió la visualización de realidades no explicables a la luz de la teoría económica convencional, en razón de no ubicar únicamente los factores de tierra, trabajo y capital, sino que muestra otros aspectos que garantizan la cohesión de las organizaciones y su permanencia en el tiempo. De igual manera, se hizo un intento de acercamiento cuantitativo a partir de información suministrada por las administraciones municipales y otras entidades gubernamentales.

\section{Contextualización de la región}

Los municipios de Alejandría y Concepción pertenecen a la zona de Embalses, y San Vicente Ferrer a la zona de Altiplano, de la subregión Oriente del departamento de Antioquia. Históricamente, estas zonas encontraron en el sector agropecuario su fuente primaria de sustento económico. Allí se asentaron asociaciones y cooperativas dedicadas a esta actividad con potencialidades que redundan en desarrollo. Se analizaron en total 24 organizaciones campesinas de estos municipios.

Las unidades de análisis se constituyen en los municipios de San Vicente Ferrer, Concepción y Alejandría. En el mapa (figura 1), puede apreciarse la condición de los municipios, según lo cual San Vicente se encuentra a una distancia aproximada de $15 \mathrm{~km}$ de la arteria vial más importante del país: la autopista Medellín-Bogotá, al igual que cerca de Medellín y al Aeropuerto Internacional José María Córdova de Rionegro.

De la cantidad de asociaciones existentes en el municipio, muchas - aunque con características asociativas- no tienen dentro de su objeto social el desarrollo de actividades propiamente agropecuarias. Si bien se incluyen algunas asociaciones de transformación (como

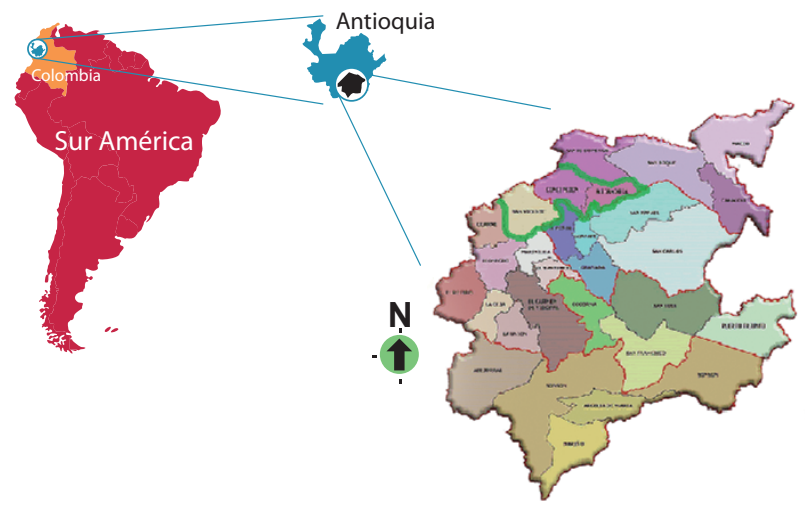

Figura 1. Ubicación de los municipios de análisis en el oriente antioqueño. Modificación a partir de información suministrada por los municipios.

es el caso de los productores de miel y de panela), se incluyeron porque sus productos están íntimamente ligados a la producción agropecuaria. La distribución de las asociaciones analizadas se da tal como lo establece la tabla 2, siendo Concepción, de los tres municipios, el que cuenta con un mayor número de asociaciones de carácter agropecuario y de pequeños y medianos productores (41,67\%). Sin embargo, más adelante (tabla 3) se evidencia que la mayor participación agropecuaria se encuentra en el municipio de San Vicente.

Tabla 2

Total de asociaciones analizadas

\begin{tabular}{lcc}
\hline \multicolumn{1}{c}{ Municipio } & Total asociaciones & Participación \% \\
\hline Concepción & 10 & 41,67 \\
San Vicente Ferrer & 9 & 37,5 \\
Alejandría & 5 & 20,83 \\
\hline Total & $\mathbf{2 4}$ & $\mathbf{1 0 0}$ \\
\hline
\end{tabular}

Nota. Elaboración propia

El municipio de San Vicente Ferrer se caracteriza por ser es el más grande territorialmente de los municipios analizados, además de encontrarse más cerca de la autopista que une a Medellín y Bogotá, además del hecho de encontrarse también más cerca de Rionegro. Es el único de los tres municipios que pertenece a la zona Altiplano. Su mayor participación agropecuaria puede deberse al hecho de que en los municipios vecinos se presentan escapes productivos que luego son contabilizados en el municipio de San Vicente Ferrer. 
Tabla 3

Participación agropecuaria por municipio

\begin{tabular}{lcc}
\hline \multicolumn{1}{c}{ Municipio } & \% unidad agro & \% unid.(ha) \\
\hline Alejandría & $11,0 \%$ & $15,35 \%$ \\
Concepción & $18,8 \%$ & $84,24 \%$ \\
San Vicente & $70,2 \%$ & $0,41 \%$ \\
\hline
\end{tabular}

Nota. Elaboración propia con datos del DANE

De los tres municipios investigados, el municipio de San Vicente (zona Altiplano) presenta el mayor porcentaje de unidades agropecuarias con más del 70\% de las unidades estudiadas. A pesar de que porcentualmente solo presenta el $37,5 \%$ de las organizaciones de carácter agropecuario. Puede decirse que la existencia de este nivel de unidades agropecuarias no implica necesariamente la existencia de procesos asociativos o cooperativos en el municipio, si bien se puede determinar una mayor participación productiva de San Vicente en relación con los demás municipios estudiados. En este se da por la mayor extensión territorial que lo caracteriza, además del hecho de encontrarse más cerca de Rionegro y Medellín, con las respectivas vías de acceso, lo cual permite además que se contabilicen en el municipio escapes de los otros municipios cercanos que no cuentan con las ventajas de ubicación que tiene San Vicente.

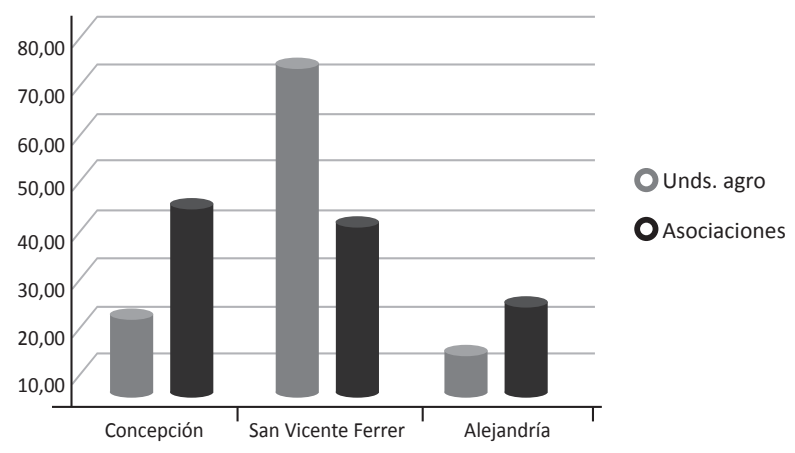

Figura 2. Participación agropecuaria, por unidades agropecuarias y por asociaciones de los municipios. Elaboración propia con datos del DANE.

En la figura 2 puede apreciarse la preeminencia del municipio de San Vicente Ferrer en cuanto a unidades productivas de carácter agropecuario. En este sentido, la producción agropecuaria es mayor en el municipio de San Vicente, no así el número de asociaciones que se destinan a este tipo de actividad. Son los municipios de Concepción y Alejandría los que se caracterizan precisamente por la preeminencia de este tipo de actividades productivas, realizadas por asociaciones, lo cual indica cómo la actividad productiva de San Vicente, si bien es la de mayor número en términos agropecuarios, se da por actividades de carácter personal o familiar y no necesariamente vinculada a organizaciones tales como asociaciones y cooperativas.

\section{Una mirada a la economía solidaria de los municipios de San Vicente Ferrer, Alejandría y Concepción}

Aunque las asociaciones de estos municipios se caracterizan por la limitada capacidad de recursos de carácter financiero y de medios materiales - la existencia de estos elementos es extremadamente pobre ya que se limitan a tener las herramientas, utensilios y bienes estrictamente necesarios para la producción de los bienes agrícolas definidos en sus respectivos objetos sociales-, mantienen la voluntad de mantener viva la asociación como mecanismo que garantice una calidad de vida digna. Esto se evidencia en cuanto es posible establecer relaciones cohesionantes. Es decir, la existencia de algún elemento particular que pueda ser utilizado socialmente permite que la propiedad no sea de carácter individual sino que pueda ser colectiva; la propiedad, al ser de todos, no le pertenece a nadie sino que se aprovecha la existencia de la personería jurídica de la asociación para hacer uso de ella, como es el caso de los trapiches comunitarios que permiten el proceso de transformación de la caña de azúcar en panela y sus derivados. Esto además permite que los procesos de innovación necesarios, producto tanto de la demanda misma del producto, como de factores exógenos como las exigencias de carácter fitosanitarios, también sean asumidos de forma socializada. Sin embargo, en muchos casos presentan problemas ya que implica la asignación adicional de recursos, muchas veces inexistentes para garantizar la continuidad de la asociación como elemento cohesionante de asociatividad.

Con respecto a los caminos de la economía de la solidaridad, es posible aseverar que la producción campesina es la que mayor importancia productiva tiene en los municipios. Se evidencian inmigraciones a otros sectores acompañados de emigraciones a grandes 
ciudades. Sin embargo, la forma tradicional de explotación de los recursos naturales en el sector primario de la economía, antes de ser un problema grande del desarrollo, podría posibilitar opciones de mejoramiento continuo y alternativas hacia un desarrollo más humano y no tanto económico. Empero, el crecimiento del sector agrícola y sus eventuales necesidades por productos podrían establecer una serie de ventajas comparativas que podrían ser explotables, dada la cercanía del municipio al Aeropuerto de Rionegro. Esto redundaría en un mejoramiento de las condiciones de vida mediante la creación de empleo, la posibilidad de reinversión en tecnología que mejore los procesos de producción y la posibilidad de establecer un crecimiento económico importante que le permita incluirse dentro de la dinámica de la ciudad metropolitana.

Existe, asimismo, un predominio de la economía campesina de autosubsistencia y con algún tipo de vinculación con el mercado. Sin embargo, la producción de valor es escasa debido principalmente a la limitada utilización de capital, por lo cual el factor comunidad parece ser indispensable para el mantenimiento de estas asociaciones en el tiempo. Esto en relación con la constante fluctuación de los precios de mercado de los productos y la limitada productividad de este sector, además de las variaciones de la población, las cuales desde el periodo de la violencia han sido inconstantes, no solo en el proceso de emigración hacia las grandes ciudades, sino también por el arribo de nuevos habitantes, los cuales muchas veces chocan con la realidad productiva de la región. Sin embargo, esto no ha redundado en una mejora sustancial de las condiciones de vida de los habitantes, en cuanto a que no ha generado empleos de gran duración y el número marginal de empleados que utiliza mayoritariamente son traídos de otra región.

Con todo, puede decirse que la importancia de los medios materiales es fundamental para la conformación y consolidación del factor comunidad, dentro de la óptica de la teoría económica comprensiva propuesta por Razeto (1994). Esto en cuanto son los medios materiales los que permiten esa relación de asociatividad entre los diferentes miembros de la asociación y se constituyen en relaciones de solidaridad, camaradería y compañerismo. No como una identificación propia como subjetividad colectiva, sino como la conformación de una entidad que permite, dentro de la misma diferencia y los intereses diferenciables, establecer una serie de prioridades y la conformación de unos intereses sociales o solidarios que permiten la continuidad de la asociación, tanto como entidad jurídica, como ente de direccionamiento comunitario hacia el mantenimiento de condiciones de subsistencia y condiciones de vida específico de este tipo de comunidades.

\section{Conclusiones y reflexiones finales}

Podría pensarse que una organización vinculada a la economía solidaria no debería:

1. Derivar su actividad principal a acciones propiamente financieras, aunque esto no signifique que no pueda ser una entidad que permita la captación de recursos para que funja como entidad "redistribuidora" dentro de las demás entidades de economía solidaria, evitando, en todo caso, el cobro de intereses. Esto necesariamente implicaría la aplicación de un sistema alternativo desde el punto de vista monetario que pueda evitar los efectos inflacionarios o, por lo menos, el cobro de la retribución debe ser exactamente lo correspondiente a la pérdida del poder adquisitivo de la moneda (en el caso de la existencia de créditos). Esto es posible afirmarlo, no en términos de garantizar la existencia de esta organización en condiciones en las que prima la estructura capitalista, sino, quizás, desde una perspectiva más bien romántica basada en el carácter axiológico de la economía solidaria.

2. Observar a los demás agentes que se destinen a actividades productivas similares como "competencia", sino más bien como colaboradores de un mismo proceso que permita a los agentes demandantes las decisiones a partir de sus gustos personales y necesidades específicas. Se trata de evitar, en todo caso, los procesos especulativos y variaciones estrepitosas de precios que perjudiquen el flujo pecuniario tanto de la organización solidaria inicial como la de su vecino. Al tiempo, permitir verse como proveedoras de experiencias, conocimientos y hasta de los mismos productos.

3. Negar el acceso a la información de manera libre y "democrática", además de la libre movilización de los agentes, pero con condiciones de solidaridad. Esto, por lo tanto, concedería el cumplimiento de los supuestos tradicionales de la economía clásica en el caso de competencia perfecta, pero ya en términos "democráticos".

4. Dejar de establecer una red de integración diferente a las propuestas por las escuelas de administración, es decir, una red propia de una economía de 
la solidaridad, en la cual no se propenda hacia el establecimiento de estructuras oligopólicas o monopólicas, sino donde todo el sistema se mantenga en equilibrio constante, precisamente por la coexistencia de los subsistemas que lo componen.

Desde las acciones que se pueden realizar desde la academia, se encuentra la del estudio y aproximación teórica de alternativas para la economía solidaria, identificando los motivantes axiológicos que fundamentan el pensamiento tradicional, y de esta manera presentar las propuestas alternativas desde esos mismos motivantes y empezar a construir desde lo ya hecho, lo cual permita la construcción del proyecto de la economía solidaria. Y así, como la fundamentación de la economía clásica se basa en elementos metafísicos y conceptuales, establecer relaciones que hagan de la economía solidaria una realidad.

Una posible forma en la que se puede constituir el sector de la economía solidaria en términos reales se encuentra en la identificación de las organizaciones que la componen en su condición de economía solidaria, dejando a un lado las limitaciones conceptuales según las cuales solo ciertas formas de asociatividad se podrían relacionar con el término. Por último, dejar de identificar únicamente al cooperativismo como economía solidaria, así como la economía popular, la economía campesina y los demás "caminos" de la economía solidaria.

\section{Referencias}

Confecoop. (2009). Las cooperativas de trabajo asociado. En Observatorio Cooperativo, 11. Recuperado el 12 de marzo del 2014 de: http://www.confecoop.coop/observatorio/11/files/doc11.pdf

Congreso de Colombia. (Agosto 4 de 1998). Ley 454 de 1998. Por la cual se determina el marco conceptual que regula la economía solidaria, se transforma el Departamento
Administrativo Nacional de Cooperativas en el Departamento Nacional de la Economía Solidaria, se crea la Superintendencia de la Economía Solidaria, se crea el Fondo de Garantías para las Cooperativas Financieras y de Ahorro y Crédito, se dictan normas sobre la actividad financiera de las entidades de naturaleza cooperativa y se expiden otras disposiciones. Do N. ${ }^{\circ} 43357$.

Forero, J. (2003). Economía campesina y sistema alimentario en Colombia: aportes para la discusión de la seguridad alimentaria en Colombia. Disponible en: http://www. javeriana.edu.co/fear/d_des_rur/documents/campesinadoysistemaalimentarioencolombia.pdf

Guerra, P. (2008). La incidencia política del movimiento de la Economía Solidaria en América Latina. Periódico Digital Mercado Justo, 3(7). Disponible en: http://fecootra. coop

Jiménez-Arcila, F. (1930). Cooperativas de consumo. Medellín: Universidad de Antioquia.

León XiıI. (1891, 15 de mayo). Carta encíclica Rerum Novarum del Sumo Pontífice León XII sobre la situación de los obreros. Disponible en http://www.vatican.va/ holy_father/leo_xiii/encyclicals/documents/hf_l-xiii_ enc_15051891_rerum-novarum_sp.html.

Programa de las Naciones Unidas para el Desarrollo. (PNUD) (2011). Colombia rural: razones para la esperanza. Informe Nacional de Desarrollo Humano 2011. Bogotá: INDH-PNUD.

Razeto, L. (1994). Fundamentos de una Teoría Económica Comprensiva. Santiago de Chile: Ediciones PET.

Razeto, L. (1997). Los caminos de la economía de solidaridad. Buenos Aires: Lumen Humanitas.

Razeto (2014). Economía de la solidaridad. Recuperado el 17 de abril del 2014 de: http://www.uvirtual.net/spuv/ catedra-latinoamericana-de-economia-solidaria.

Smith, A. (1776/1958). Indagación sobre la naturaleza y causa de la riqueza de las naciones. México: Fondo de Cultura Económica.

Sociedades Bíblicas en América Latina (1960). Nuevo testamento, Salmos y Proverbios. The Giodeons International. 